\title{
12 Sexual harassment in public spaces in India
}

\section{Victimization and offending patterns}

\author{
Mahesh K. Nalla
}

\subsection{Introduction}

Over the past decade, sexual harassment $(\mathrm{SH})$ of women in public spaces as a form of violence against women has received considerable attention in both developing and developed countries. SH, an improper behavior that has a sexual dimension and intonations includes nonverbal, verbal, and physical actions, mostly by males, toward females at any time of the day or night (Neupane \& Chesney-Lind, 2014; Madan \& Nalla, 2016). By "sexual harassment in public spaces" we mean forms of SH provocations that are not limited to what occurs on public streets, parks, and marketplaces but includes public transport spaces such as buses, bus-stops, trains and train stations, and other public transit spaces.

India, like many other countries, is no exception to the occurrence of $\mathrm{SH}$ (Jagori \& UN Women, 2011). SH is widespread, particularly in mega-cities such as Delhi, where, for over 98 percent of the population, public transport (including taxis and auto-rickshaws) is the only means to get to work, school, or attend to family matters (Madan \& Nalla, 2016). The insecurities of urban spaces and $\mathrm{SH}$ in public spaces drew worldwide attention following an event that occurred in 2012 in Delhi, India. A 23-year-old woman was sexually harassed in a moving public bus by a group of young men, including the driver and the conductor. This harassment escalated to the victim being beaten-up, gang raped, and brutally tortured, resulting in her death. This incident, which later came to be referred to as Nirbhaya (the fearless, who tried to fight off the six offenders) drew thousands of protestors - facilitated through social media and the media-who spilled into the streets all over the country demanding government action to this extremely pervasive and much neglected form of violence against women.

While there is a smattering of literature on the subject in India, most of the prior work focuses on $\mathrm{SH}$ victimization in public spaces, and we found very little work that focuses on offenders. The aim of the current research is to examine the extent of sexual harassment in public spaces in India with a focus on victimization as well as the self-reported behaviors of offenders. Additionally, we examine the congruence between reported victimization rates and self-reported offending patterns as well as $\mathrm{SH}$ offending patterns of their male friends. 


\subsection{Theoretical considerations}

For many developing countries, particularly in South Asia, $\mathrm{SH}$ in public spaces remains a concern because of traditional cultures and religions that have a bearing on women's place in public spaces (Niaz, 2003). Prior research, which is grounded in the framework of the patriarchy, identifies structural forces that influence male dominance and masculinity, which in turn shape gender roles in social and economic spheres (Acker, 1992; Hearn \& Parkin, 2001). MacKinnon (1979), drawing on observations based on socio-cultural perspectives, noted that $\mathrm{SH}$ occurred in societies with unequal power distance and where sexual requirements are imposed on the "weaker" party, in this instance, women. The work of MacKinnon (1979) and others (e.g., Uggen \& Blackstone, 2004) suggests that men and women are socialized differently with varying expectations among genders. For instance, men are stereotypically expected to pursue qualities of domination, leadership, and sexual initiative while women are expected to be submissive and nurturing, resulting in men often pursuing women to gain power and self-interest (Luthar \& Luthar, 2007).

Other competing theoretical perspectives that shed light on and are relevant to SH victimization relate to work advanced by Cohen and Felson (1979), which suggests that victimization is likely to be higher when people remove themselves from their routine activities. This could lead people (in this case, women) to have diminished guardianship, creating more opportunities for motivated offenders. Applying these principles to SH, Ceccato (2014) observed that the likelihood of $\mathrm{SH}$ victimization occurring increases when a potential victim intersects with a motivated offender in the absence of or decreased vigilance. Victimization is often interconnected to personal and lifestyle characteristics, many of which are unavoidable, such as going to school, work, and running errands (shopping, visiting family, etc.) (Tseloni \& Pease, 2004). Furthermore, in countries such as India, which is the second-largest producer of fruits and vegetables in the world, women represent nearly 50 percent of those employed in the supply chain of fruit, vegetables, fresh produce markets and small businesses. This creates greater opportunities for them to be in public spaces (Gurung, 2006). For many of these women, public transportation is the only means to get around, and it is often inadequate relative to the population, resulting in overcrowding and thus creating greater vulnerability to women commuters (Parikh, 2018).

\section{Prior research on SH in public spaces in India}

A number of studies on $\mathrm{SH}$ of women in public spaces in both developed (Macmillan, Nierobisz, \& Welsh, 2000) and developing countries (for a review see Madan \& Nalla, 2016; Ceccato \& Paz, 2017) have addressed gender violence in public spaces. In India, in the past decade, many studies have addressed gender violence specifically related to sexual harassment. There were a few researchers who addressed women's safety and how they negotiate everyday 


\section{Mabesh K. Nalla}

risks in public spaces in metro cities such as Mumbai (Phadke, 2005; Bharucha \& Khatri, 2018), Kolkota (Sur, 2014), Chennai (Natarajan, 2016) and other smaller cities in northeastern India (Bhattacharyya, 2016). The findings from these studies show that an overwhelming percentage of the respondents reported public spaces as being unsafe due to fear of crime and victimization, with specifically fear of sexual harassment being the most significant factor. These findings highlight women's safety and fear of sexual violence in their everyday life, a finding echoed in Western research (Macmillan et al., 2000).

One of the earliest surveys examining the incidence of $\mathrm{SH}$ in public spaces (buses) prior to the Nirbhaya incident was conducted in the South Indian city of Chennai with a small sample of respondents $(N=100)$ (Chockalingam \& Vijaya, 2008). Findings showed a high incidence of female victimization in the age group of 15-35 who had experienced unwanted touching and groping. The offenders were described by their victims to be between 35 and 70 years old, well-dressed and seemingly educated, and targeting women who wore nontraditional South Indian clothes.

One of the most systematic studies done to assess $\mathrm{SH}$ victimization in public spaces in Delhi in $2010(N=5,000)$ highlighted the various forms of sexual harassment women face while in public spaces such as markets, bus terminals and roadsides (Jagori \& UN Women, 2011). The report found that nearly 66 percent of women and girls experience $\mathrm{SH}$ in public spaces with 51.4 percent reporting public transport buses as the most common public spaces where maximum sexual harassment occurs. This finding is not surprising given that, in metro cities such as Mumbai, an estimated 88 percent of the residents rely on public buses and metros, and in Delhi 43 percent of residential households rely on public transport (Badami \& Haider, 2007). The inadequate public transport services in India's cities contribute to overcrowded situations (Pucher, Korattyswaroopam, \& Ittyerah, 2004) making it easier for offenders to participate and escape detection after committing $\mathrm{SH}$.

Despite the significance of the Nirbbaya incident in 2012, very few studies have since been conducted in India that addressed this issue. One of the earliest studies following Nirbhaya was a study conducted with a small convenient snowball sample of 20 women, aged 18 to 30 years, from the middle and upper-middle classes in Delhi (Dhillon \& Bakaya, 2014). Interviews with respondents on their experiences in the city revealed that between 50 percent and 100 percent reported some form of $\mathrm{SH}$ as they commuted to work or walked to the market, to a movie theater, or, in essence, used public spaces.

One of the few large-scale systematic research studies was conducted in Delhi Metro area in 2014, drawing a sample of 1,387 males and females by employing a multistage cluster and quota sampling technique (Madan \& Nalla, 2016). The findings show that public transport was the main mode of transportation for nearly 99 percent of males and females. Compared with males (50.9 percent), females (26.8 percent) felt unsafe in public spaces and over half the women in the sample reported being a victim (57.6 percent) of $\mathrm{SH}$ or knew a friend or family member who was a victim (48.3 percent) in the last 12 months 
(Madan \& Nalla, 2016). Overall, while there is a general congruence between genders in terms of seriousness of $20 \mathrm{SH}$ behaviors, the differences, however minor, were statistically significant with women rating them as more serious (Madan \& Nalla, 2016).

A more recent study with a sample of 1,600 respondents who travel by public buses, drawn from multiple cities in India, reported that 554 (34.9 percent) reported sexual harassment with groping being the most frequent, more often than even catcalls and sexually-laced comments (Lea, D'Silva, \& Asok, 2017). A survey of 300 women in Mumbai, selected randomly from among those walking in the market areas and to and from metro stations, revealed that 77.2 percent experienced $\mathrm{SH}$ in the form of lewd comments, catcalls, and insinuating songs. Additionally, 30 percent reported stalking, 29 percent reported being groped, and 7 percent molested (Bharucha \& Khatri, 2018). Using a convenient but systematic sample of 200 female students from two women's colleges in Lucknow in the state of Uttar Pradesh, another study assessed the incidence and frequency of $\mathrm{SH}$ victimization experienced in a variety of modes of transportation, which included buses, taxi-cabs, threewheeled min-cabs (Tripathi, Borrion \& Belur, 2017). Findings from this study confirmed findings from prior research (Madan \& Nalla, 2016) in that of all forms of public transportation, buses were considered the least secure and 100 percent of the respondents indicated that they were either personally a victim or witnessed a physical or verbal form of SH. Given that data are from college students, the findings of the Lucknow study, as in other studies (Dhillon \& Bakaya, 2014; Neupane \& Chesney-Lind, 2014), finds young women at greater risk of SH. Findings from the central Indian city of Bhopal reveal that 88 percent of women were harassed while using public transport and 40 percent reported facing harassment on a regular basis (Bhatt, Menon, \& Khan, 2018). Interestingly, however, 100 percent of public bus drivers and conductors did not believe it was a prevalent issue and another 30 percent believe that women were equally responsible for SH perpetrated against them (Bhatt, et al., 2018).

Unlike serious sexual offenses such as rape, which has the propensity to occur more frequently among acquaintances and other non-strangers, $\mathrm{SH}$ is more prevalent among strangers (Macmillan et al., 2000). Among the reasons for the causes of $\mathrm{SH}$, the respondents felt that migrant men from small towns are not only patriarchal but "awed" by Delhi women who are independent and travel alone, prompting men to demean or sexually harass women to put them down (Dhillon \& Bakaya, 2014). The reasons attributed by female victims of SH for men engaging in SH were slightly different in another study from a Southern Metro city of Chennai. Natarajan (2016, p. 6) noted that college students attributed the reasons to patriarchy ("male domination," "discrimination," "cultural values"), differential ("socialization of boys and girls") and situational ("alcohol," "boredom," "more women seeking education and employment" and "lack of bystander intervention") reasons. Among the reasons attributed to males' behavior for this were a patriarchal mindset (77 percent), absence of fear of the law ( 57 percent), lack of effective police patrol (45 percent), poor street 
lighting (13 percent), and women's choice of apparel (11 percent). These findings are similar to other prior studies (Natarajan, 2016).

In summary, four major themes emerge from prior research. The first theme relates to women's fear of public spaces and the associated fear of victimization. The second thread relates to the high incidence and prevalence of victimization among younger women of various forms of $\mathrm{SH}$ occurring in a variety of public spaces. The third relates to gender differences in perceived seriousness of $\mathrm{SH}$. The final theme relates to victims' perceptions of why males engage in $\mathrm{SH}$. While this research adds to our understanding of $\mathrm{SH}$ prior research, with the exception of a couple of studies, findings are often drawn from sample sizes employing a convenient sampling framework with a focus exclusively on the incidence of $\mathrm{SH}$ in general with a limited focus on victims. This exploratory research therefore attempts to contribute to the sparse literature on $\mathrm{SH}$ with greater attention to offenders' self-reported participation in SH behaviors. More specifically, we examine (1) the gender differences in perceptions of imagery of what constitutes $\mathrm{SH}$; (2) a comparison of the awareness of $\mathrm{SH}$ laws and their enforcement between victims and offenders; (3) congruence in the rates of reported female victimization of SH and males' self-reported offending; and, (4) congruence between self-reported offending and male friends' participation in $\mathrm{SH}$.

\subsection{Current study}

\section{Context}

In India, street sexual harassment is euphemistically referred to as "eve-teasing", a long recognized social problem and a reference that trivializes the seriousness of various forms of offensive behaviors against women. This phrase interestingly, however, does not appear in any Penal Codes in India. Worse, such behaviors are not taken seriously, and are accepted as a minor nuisance and a lighthearted ritual associated with young men's transition to adulthood. Others suggest that these behaviors are often brushed off by men as jocular and lighthearted practices that are validated culturally across the country (Bhattacharyya, 2015).

Delhi, the National Capital Territory (NCT), India, with over 18 million people is the fifth most populous city in the world. Delhi has the highest recorded crime compared with all other geographic distributions in India according to the 2016 National Crime Record Bureau (NCRB) report (2017) and is considered one of the most unsafe cities in the world (Gaynair, 2013). Delhi NCT also reported the highest rate of crimes against women for rape and other sexual offenses per 100,000 women in India (86.96 compared to a national average of 22.16) (National Crime Records Bureau, 2015, p. 24). Among crimes against women, Delhi also has the distinction of highest rate of crimes per 100,000 relating to sexual harassment under the categories of Insult to the modesty of women (15.1 vs. 1.6 national average), and Assault on women with intent to outrage her modesty (47.9 vs. 13.7 national average) (National Crime Records Bureau, 2015, p. 32). 


\section{Data and method}

Data for the study were drawn from a larger study conducted in 2014. Drawing from prior work (Jagori \& UN Women, 2011; Neupane \& ChesneyLind, 2014), and contextualizing it to the local cultural setting, we constructed a survey questionnaire (bilingual, English and Hindi) drawing from various themes pertaining to sexual harassment in public spaces. A total of 20 sexual harassment behaviors were identified that fell into three broad categories (listed in Table 12.3, later): nonverbal, verbal, physical. In addition, all of these behaviors are cited as examples in the Indian Penal Code under various sections noted above. All respondents (both male and female) were asked to rate the seriousness of behaviors constituting sexual harassment on a seven-point scale $(0=$ not at all serious, $1=$ not serious, $2=$ less serious, $3=$ neutral, $4=$ somewhat serious, 5 = serious, $6=$ very serious).

\section{Sample}

Using multistage cluster and quota sampling strategies, we drew between 250 and 275 respondents from each of the five primary zones (North, East, West, South and Central) in Delhi, the capital city of India. Data collection for this study lasted nearly 60 days (pencil and paper method) and resulted in a total of 1,387 respondents ( male $=621 / 45$ percent; female $=766 / 55$ percent). The demographic breakdown of the respondents is presented in Table 12.1 .

The educational background of victims and offenders was fairly evenly distributed: primary $=23.3$ percent vs. 23.6 percent; secondary $=24.8$ percent vs . 22.4 percent; high school=22 percent vs. 29 percent; and, college and higher $=30.5$ percent vs. 24.8 percent. A similar distribution was apparent in monthly income levels ( 1 US\$ = Indian Rupees ₹ 72), for victims and offenders: those earning less than $₹ 10,000=54.8$ percent vs. 47.4 percent; $₹ 10,001$ to $25,000=23.5$ percent vs. 33.9 percent; and, those earning $₹ 25,001$ and more $=21.7$ percent vs. 17.7 percent. Nearly 77 percent of the victims and 65 percent of the offenders were ever married (includes currently married or married in the past).

Regarding place of residence, 92.9 percent out of 766 females live in Delhi. Among males, 87.8 percent of the 621 live Delhi. 93.8 percent of victims and 87.2 percent of offenders live in Delhi. However, relative to the number of victims (6.2 percent) who live on the fringes of the city (e.g., Noida, Ghaziabad, Gurgaon, and Faridabad), there were nearly twice as many offenders (12.8 percent) from outside Delhi. Given the small number of $N$ for participants living outside Delhi, these percentages appear exaggerated.

The primary purpose of the use of public transportation for the majority of victims (75 percent) compared with offenders (39.7 percent) was visiting friends, family and shopping. A majority of the offenders are employed (78 percent). However, 43.1 percent of offenders, compared with 5.8 percent victims use public transportation for work or business. This suggests that a 
Table 12.1 Descriptive statistics of victims $(N=467,60.7 \%)$ and offenders $(N=317)$

\begin{tabular}{|c|c|c|}
\hline Categories & $\% *$ victims & $\%$ * offenders \\
\hline \multicolumn{3}{|l|}{ Education } \\
\hline l = Primary education & 22.8 & 23.6 \\
\hline $2=$ Secondary education & 24.8 & 22.4 \\
\hline $3=$ High school & 22.0 & 29.0 \\
\hline $4=$ College and above & 30.5 & 24.8 \\
\hline \multicolumn{3}{|l|}{ Income (per month, in INR) } \\
\hline $1=$ Less than 10,000 & 54.8 & 47.4 \\
\hline $2=10,001-25,000$ & 23.5 & 33.9 \\
\hline $3=25,001$ and above & 21.7 & 17.7 \\
\hline \multicolumn{3}{|l|}{ Relationship status } \\
\hline $1=$ Never married & 22.6 & 34.9 \\
\hline $2=$ Ever married & 77.4 & 65.1 \\
\hline \multicolumn{3}{|l|}{ Place of residence } \\
\hline l = Delhi & 93.8 & 87.2 \\
\hline $2=$ Around Delhi* * & 6.2 & 12.8 \\
\hline \multicolumn{3}{|l|}{ Public transport-purpose } \\
\hline $1=$ Visit friends $/$ family $/$ shopping & 75.0 & 39.7 \\
\hline $2=$ School $/$ college & 16.2 & 17.7 \\
\hline $3=$ Work $/$ business & 5.8 & 43.1 \\
\hline $4=$ Other & 3.2 & 3.7 \\
\hline
\end{tabular}

majority of offenders who harass women are employees who commute to and from work.

\subsection{Imagery of sexual harassment}

One of the questions in the survey related to capturing respondents' imagery of behaviors that constitute SH. All females $(N=766)$ and males $(N=621)$ were asked to describe what sexual harassment means to them, to which 1,201 and 1,016 comments were received from females and males respectively. These responses were coded to group comments that fit into broader themes and categories (Figure 12.1). The most common imagery of $\mathrm{SH}$ for both females (28.1 percent) and males (26.7 percent) is sexual teasing/jokes and comments, suggesting a close resemblance between the two groups of respondents. An interesting imagery that was reported by both females and males are "forceful sexual relations/rape," which is a more violent form of sexual crime, and "forceful attempt to kiss/have sex". Although, comparatively, more females' (14.6 percent) compared with males' (9.3 percent) imagery of $\mathrm{SH}$ was described as rape, a similar disparity in the opposite direction was found for females (13.3 percent) and males (21.6 percent) regarding forceful attempt to kiss/have sex. Together, 


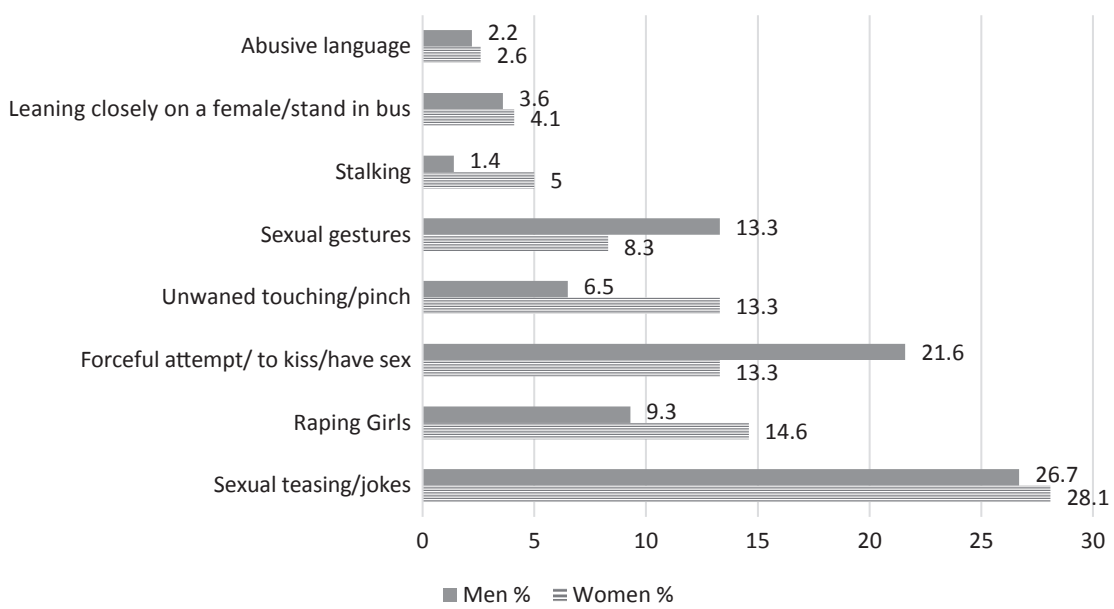

Figure 12.1 Percentage comparisons of the imagery of $\mathrm{SH}$ for females $(N=766)$ and males $(N=621)$

these two categories represented close to a third of all imagery related to sexual harassment. Nearly twice as many females (13.3 percent) compared with males (6.5 percent) described unwanted touching and pinching as imagery associated with $\mathrm{SH}$, while fewer females (8.3 percent) reported sexual gestures representing SH compared with men (13.3 percent). More women ( 5 percent $)$ described stalking as SH experience compared with males (1.4 percent) while the numbers and the gap for genders relating to leaning closely on a female or using abusive and profane language was rather small. Comments that were undecipherable or representing similar images noted in the figure were not represented.

\subsection{Profiles of victims and offenders-age}

The average age of the respondents is 36.3 years. The age range for the victims was 18 to 74 and the youngest age at which a victim first reported SH experience was 10 years of age. For offenders, the age range was 18 years to 80 years old; however, that survey did not have the question regarding the age at first time offending in the survey. Description relating to age break down for both victims and offender is presented in Figure 12.2. The trend lines suggest that there is a close alignment in spikes and lows for both groups for the ages around 24 through 50 years.

A closer look at the breakdown of age groups for prevalence of victimization and offending shows some categories that are more compatible. Twenty-seven percent of victims and 30.3 percent of the offenders were in the age group of 18 to 25 years. However, an overwhelming majority of 80.7 percent victims and 71.8 percent offenders were 40 years and under. Among the offenders, close to 


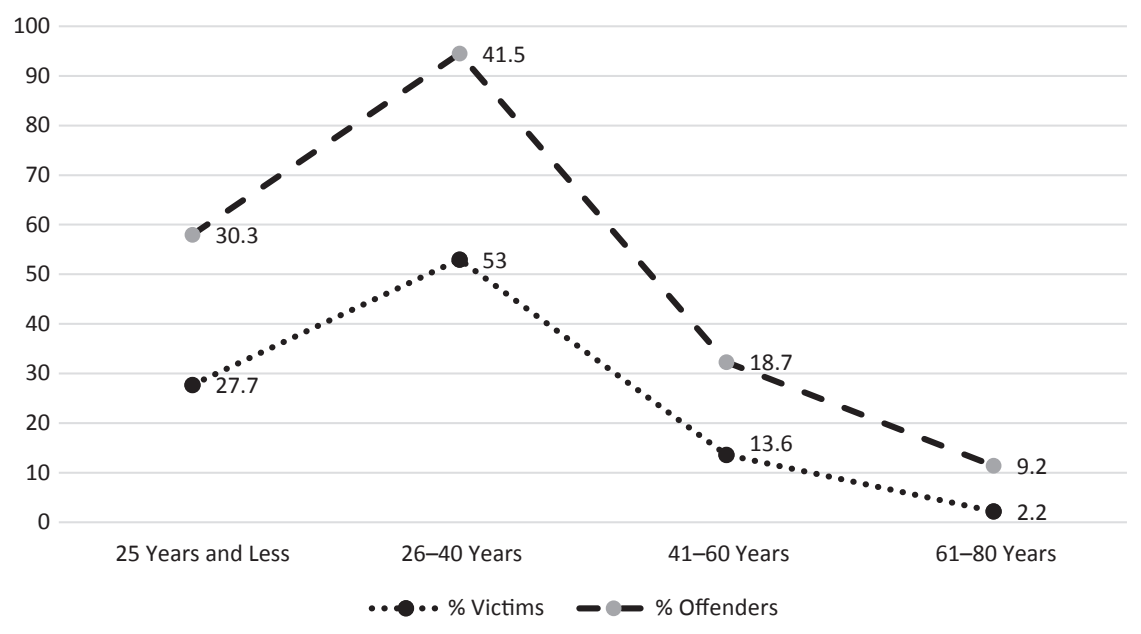

Figure 12.2 Frequency and age distribution of victims and offenders.

a third were 40 years and above with 12 percent in the age group of $41-50$, 6.7 percent in the age group of 51-60. A surprising finding from our data was that 9.2 percent of offenders were in the age group of 61 and above compared with only 2.2 percent of victims. Even more interesting is the finding of senior citizens $(N=11,3.4$ percent) self-reporting as offenders were in the age group of 70 and 80 years.

\section{Victims/offender views on awareness and effectiveness of SH laws}

A vast majority of the victims (83.5 percent) and offenders (95.8 percent) are aware of the Nirbhaya event (Figure 12.3). Surprisingly, however, only about two-fifths of the victims (38.1 percent) and offenders (42.2 percent) are aware of laws that punish $\mathrm{SH}$ offenders. Less than a third of victims believe the effectiveness of SH laws (30.8 percent vs. 29.2 percent) or that $\mathrm{SH}$ laws are effectively enforced (30.9 percent vs. 33.8 percent). However, the respondents had more positive views of the role of media in informing citizens about $\mathrm{SH}$ (58.5 percent vs. 46.9 percent).

\section{Victimization and self-reported offending}

From among the 766 females in the sample, 467 (61 percent) reported one or more forms of sexual harassment and 425 women ( 55.5 percent) knew a friend or family member who was victimized. Among the victims, 325 (42.2 percent) noted that they were harassed in the last 12 months, of whom a fifth were harassed at least once, 17.4 percent between two and five times, and 5 percent 


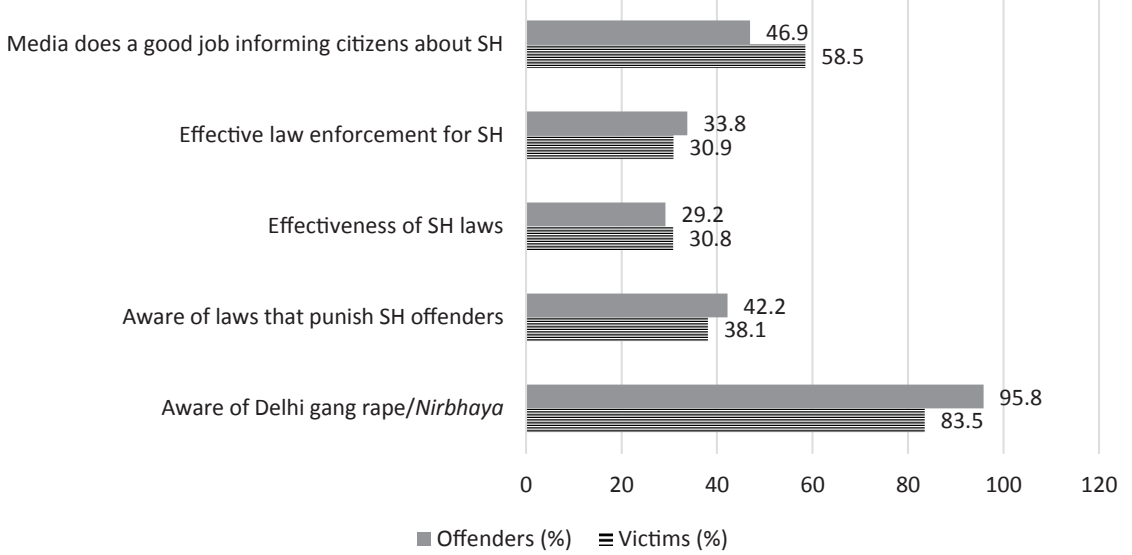

Figure 12.3 Percentage of victims $(N=467)$ and offenders $(N=317)$ awareness of SH laws and their effectiveness.

six or more times. Seventy-nine percent of these victimizations occurred during daytime. From among the sample of 621 males, 317 (51.l percent) reported to have engaged in one or more forms of sexual harassment. The SH self-reported offenders noted they know a male friend $(N=389,62.6$ percent) who also engaged in $\mathrm{SH}$ offending.

In Table 12.2, we present the percentage comparisons of victims' reporting and self-reported offenders for 20 specific types of $\mathrm{SH}$ behaviors. In addition, for each behavior, we also presented the gap/concordance rates between the two. The findings are presented from the highest to lowest percentage of victimization experiences for each $\mathrm{SH}$ behavior. The top four forms of $\mathrm{SH}$ victimization are unwanted deliberate touch/pinching (80.9 percent), leaning closely on a female or pushing loosely/slowly (77.5 percent), standing close or brushing up against a female (68.2) and whistling (57.4 percent). In contrast, 60.5 percent of offenders admitted to leaning closely on a female or pushing loosely/slowly which was the highest percentage of self-reported $\mathrm{SH}$ behavior followed by standing close or brushing up against a female (46.2 percent), whistling (40.9 percent), and unwanted deliberate touch/pinching (38.4 percent). Compared with selfreported offending, between a third and half of all victims reported stalking (44.7 percent vs. 17.1 percent), referring as babe or honey or similar words (42.1 percent vs. 26.7 percent), unwanted sexual looks or gestures (41.3 percent vs. 7.5 percent), or using obscene or abusive language (39.1 percent vs. 9.5 percent). Among these behaviors, the largest gap or lack of concordance between victim and offender reports were found for unwanted sexual looks or gestures (33.8 percent), using obscene or abusive language (29.6 percent), and stalking (27.6 percent). It is unclear from the data if gaps exist in gender differences for certain types of non-verbal and verbal SH categories, particularly a behavior such as unwanted 
Table 12.2 Comparison of percentage of victimization $(N=467)$ and self-reported offending $(\mathrm{N}=317)$ of $\mathrm{SH}$ behaviors

\begin{tabular}{|c|c|c|c|}
\hline & Victims (\%) & Offenders (\%) & $\begin{array}{l}\text { Concordance } \\
\text { rate } \%\end{array}$ \\
\hline $\begin{array}{l}\text { Unwanted deliberate touch/ } \\
\text { pinching }\end{array}$ & 80.9 & 38.4 & 42.5 \\
\hline $\begin{array}{l}\text { Leaning closely on a female or } \\
\text { Pushing loosely/slowly }\end{array}$ & 77.5 & 60.5 & 17 \\
\hline $\begin{array}{l}\text { Standing close or brushing up } \\
\text { against a female }\end{array}$ & 68.2 & 46.2 & 22 \\
\hline Whistling & 57.4 & 40.9 & 16.5 \\
\hline Stalking/A stranger following you & 44.7 & 17.1 & 27.6 \\
\hline $\begin{array}{l}\text { Referring as a girl babe or } \\
\text { honey or similar words }\end{array}$ & 42.1 & 26.7 & 15.4 \\
\hline Unwanted sexual looks or gestures & 41.3 & 7.5 & 33.8 \\
\hline Using Obscene/Abusive Language & 39.1 & 9.5 & 29.6 \\
\hline $\begin{array}{l}\text { Unwanted sexual teasing jokes } \\
\text { remarks or comments }\end{array}$ & 30.1 & 11.3 & 18.8 \\
\hline $\begin{array}{l}\text { Kissing sounds howling and } \\
\text { smacking lips at a female }\end{array}$ & 29.3 & 12.5 & 16.8 \\
\hline Poking with penis & 26.6 & 6.2 & 20.4 \\
\hline $\begin{array}{l}\text { Sexual comments about the } \\
\text { clothing anatomy or looks }\end{array}$ & 25.8 & 8.7 & 17.1 \\
\hline Patting on the buttocks & 24.8 & 4.8 & 20 \\
\hline Putting hands on the shoulders & 23.4 & 10.3 & 13.1 \\
\hline Pulling or playing with the hair & 19.5 & 7.6 & 11.9 \\
\hline $\begin{array}{l}\text { Asking personal questions } \\
\text { about sexual life }\end{array}$ & 10.5 & 10.8 & 0 \\
\hline $\begin{array}{l}\text { Asked/asking for sexual } \\
\text { favor(s) }\end{array}$ & 8.9 & 5.9 & 4 \\
\hline $\begin{array}{l}\text { Showing pornography/ } \\
\text { naked pictures }\end{array}$ & 8.0 & 3.7 & 4.3 \\
\hline $\begin{array}{l}\text { Exposing genitals/masturbating in } \\
\text { front of the women }\end{array}$ & 3.8 & 2.5 & 1.3 \\
\hline
\end{tabular}

sexual looks or gestures as offenders may not be even aware their looks make women uncomfortable.

In the next categories comprising verbal and physical behaviors, compared with self-reported offenders, reported victimization of $\mathrm{SH}$ ranged from a third to one-fifth of total victimization rates. Among them are unwanted sexual teasing (30.1 percent vs. 11.3 percent), kissing/howling sounds/smacking lips (29.2 percent vs. 12.5 percent), poking with penis (26.6 percent vs. 6.2 percent), sexual comments about clothing/anatomy (25.8 percent vs. 8.7 percent), patting on buttocks (24.8 percent vs. 4.8 percent), putting hands on shoulders (23.4 percent vs. 10.3 percent), and pulling/playing with hair (19.5 percent vs. 7.6 percent). Of these, with the exception of pulling/playing with hair (11.9 percent) and putting 
hands on shoulders (13.1 percent), the remaining behaviors had a lower concordance rates with a gap of 17 to 20 percentage points.

Among the $20 \mathrm{SH}$ behaviors, about 10 percent or fewer victims and offenders reported $\mathrm{SH}$ experiences for four types. Among these, a comparison of victimization and self-reported offending numbers show asking personal questions about sexual life (10.5 percent vs. 10.8 percent), asked/asking for sexual favors (8.9 percent vs. 5.9 percent), showing pornography/naked pictures (8.0 percent vs. 3.7 percent), and exposing genitals/masturbating in front of women (3.8 percent vs. 2.5 percent). Of these behaviors, while the percentage of both victimization and offending were lower, the concordance rates were higher than all other forms of SH behaviors. Asking personal questions about sexual life (-0.3 percent) and exposing genitals/masturbating in front of women (1.3 percent) had the highest concordance rate while the other two had about 4 percent concordance rate.

A comparison between open-ended responses of imagery of what constitutes $\mathrm{SH}$ behaviors in Figure 12.3 and victimization rates reported in Table 12.1 show a glaring discrepancy for some categories. Though there are many other responses from the open-ended imagery question that resembles the language used in the $20 \mathrm{SH}$ behaviors listed in Table 12.2, we picked the six highest percentage responses. From among the six, just one category unwanted sexual teasing had the highest concordance rate for imagery and actual victimization (28.1 percent vs. 30.1 percent). The remaining five behaviors have a large gap in the percentage of imagery and actual victimization and are: unwanted deliberate touch/pinching (13.3 percent vs. 80.9 percent), leaning closely on a female or pushing loosely/slowly (4.1 percent vs. 77.5 percent), stalking (5 percent vs. 27.6 percent), unwanted sexual looks or gestures (8.3 percent vs. 41.3 percent), and using obscene or abusive language (2.6 percent vs. 39.1 percent).

\subsection{Self-reporting $\mathrm{SH}$ offenses versus their male friends' $\mathrm{SH}$ offenses}

In this study we also examine the concordance rates between self-reporting $\mathrm{SH}$ offenders and $\mathrm{SH}$ offending patterns of their male friends. Findings are presented in Table 12.3.

Findings from Table 12.3 show a rather high degree of correspondence between the self-reported offending patterns and those claimed to have been perpetrated by their male friends. With the exception of few behaviors (e.g., whistling, groping/squeezing breasts, and asking for sexual favors) which had a gap of 4 to 6 percentage points, the remaining behaviors differed by a margin of 3 percent or less. The greatest concordance between self-reported offending and offending by a friend was for leaning closely/pushing female, use of obscene language, patting on the buttocks, and unwanted deliberate touch/ pinching; and exposing genitals/masturbating in front of women. The congruence between self-offending and friend's offending may be a function of offenders' perpetration occurring in the company of friend/s. 
Table 12.3 Comparison of percentage of self-reported offending and offending by their male friends

\begin{tabular}{|c|c|c|c|}
\hline & Offender (\%) & $\begin{array}{l}\text { Offender's male } \\
\text { friend (\%) }\end{array}$ & Concordance \% \\
\hline $\begin{array}{l}\text { Unwanted deliberate touch/ } \\
\text { pinching }\end{array}$ & 38.4 & 37.4 & 1.0 \\
\hline Leaning closely/pushing female & 60.5 & 60.4 & 0.1 \\
\hline $\begin{array}{l}\text { Standing close/brushing } \\
\text { up against a female }\end{array}$ & 46.2 & 49.6 & -3.4 \\
\hline $\begin{array}{l}\text { Referring as a girl babe or } \\
\text { honey etc. }\end{array}$ & 26.7 & 24.3 & 2.4 \\
\hline Whistling & 40.9 & 34.9 & 6.0 \\
\hline Stalking/following you & 17.1 & 20 & -2.9 \\
\hline $\begin{array}{l}\text { Asking questions about } \\
\text { sexual life }\end{array}$ & 10.8 & 14.2 & -3.4 \\
\hline Obscene/Abusive Language & 9.5 & 9.9 & -0.4 \\
\hline $\begin{array}{l}\text { Sexual jokes/teasing jokes } \\
\text { remarks }\end{array}$ & 11.3 & 14 & -2.7 \\
\hline Pulling/playing with hair & 7.6 & 5.7 & 1.9 \\
\hline Kissing sounds/smacking lips & 12.5 & 10.1 & -2.4 \\
\hline $\begin{array}{l}\text { Sexual comments on clothing/ } \\
\text { anatomy/looks }\end{array}$ & 8.7 & 12.5 & -3.8 \\
\hline Asking for sexual favor(s) & 5.9 & 10.1 & -4.2 \\
\hline Sexual looks/gestures & 7.5 & 10.5 & -3.0 \\
\hline Putting hands on shoulders & 10.3 & 8.3 & 2.0 \\
\hline $\begin{array}{l}\text { Touching/rubbing/squeezing } \\
\text { breasts }\end{array}$ & 6.2 & 11.9 & -5.7 \\
\hline $\begin{array}{l}\text { Showing pornography/naked } \\
\text { pictures }\end{array}$ & 3.7 & 5.5 & -1.8 \\
\hline Poking with penis & 6.2 & 7.1 & -0.9 \\
\hline Patting on the buttocks & 4.8 & 4.3 & 0.5 \\
\hline $\begin{array}{l}\text { Exposing genitals/masturbating } \\
\text { in front of women }\end{array}$ & 2.4 & 3.6 & -1.2 \\
\hline
\end{tabular}

\subsection{Discussion}

In this study, we assessed victimization as well as offending patterns of $\mathrm{SH}$ in public spaces following the Nirbhaya event in 2012 in Delhi, India. One of the findings relates to perceived gender differences in the imagery related to what constitutes sexual harassment. Findings from this study suggests that imagery of SH for both a majority of offenders (30.9 percent) and victims (27.9 percent) produced an image of rape and forceful attempt to have sex, which according to the IPC are violent crimes against women and do not fall into statutes relating to sexual harassment. This finding may have some implications to understanding offenders' attitudes towards $\mathrm{SH}$ in general. That is, for some offenders, the propensity to engage in less serious forms of 
sexual violence (e.g., sexual teasing, comments, touching, etc.) may seem less harmful and more acceptable since they believe they are not engaging in what they believe is sexual harassment in the form of rape and forceful attempt to kiss or have sex with a woman. The data in this study does not offer the opportunity to tease out if such a disconnect between perceptions and actual behavior of offenders is present. Future research is well worthwhile pursuing if such a disjunction exists for some offenders.

A second finding from this research suggests that although over 95 percent of the victims and offenders are aware of Nirbhaya incident, more than half of them are not aware of the existence of laws that punish sexual harassment and close to two-thirds do not believe the effectiveness of these laws and their enforcement. This finding is critical from the perspective of $\mathrm{SH}$ prevention efforts for both victims and offenders. Clearly, government efforts to publicize the seriousness as well as the legal implications for violating SH laws is critical to preventing and mitigating these forms of crimes. Only about half of all victims and offenders believe the media does a good job of informing the public of the problem of SH. This suggests media outlets have to assume a greater role and responsibility in educating the larger population of the problem.

A third finding from this study relates to a presence of a wider age range for both victims and offenders along the age spectrum in comparison to prior research. For victims, consistent with prior literature, younger women have greater propensity for being harassed. However, findings from this study shed light on the age range of the victims that concentration of higher victimization rates is in the age group of $26-40$ years ( 53 percent). Overall, nearly 81 percent of the victims are in the age group of 18 and 40 years with the remainder in the age group of 41 and 80 years. Interestingly, however, of the latter group nearly 10 percent of all victims are 61 years and above.

Findings regarding self-reporting offenders from this research are perhaps a major contribution to the literature on SH. In contrast to the stereotype of the offender being young, good-looking, and well-educated (Natarajan, 2016), our finding shows a slightly different picture. Offenders' age groups are well distributed with about a third under 30 years of age, but, interestingly, 15.9 percent of all offenders are 51 years and above, stretching well into their 70 s. While 96 percent of all offenders heard and are familiar with the Nirbhaya case, they reported having committed $\mathrm{SH}$. Additionally, although fewer than half of the offenders $(42.2$ percent) knew there were punishments associated with $\mathrm{SH}$ offending, fewer than a third believed that neither the SH laws (29.2 percent) nor $\mathrm{SH}$ enforcement of laws (33.8 percent) were effective. These perceptions may have some impact on their behavior and willingness to engage in $\mathrm{SH}$.

\subsection{Limitations and implications for future research}

An important finding from this study is that for many of the $\mathrm{SH}$ behaviors included in this study, the concordance rates for victimization and offending is fairly significant for many categories, with the exception of behaviors that either 
require fairly deliberate physical contact or nonverbal behaviors that are obvious and noticeable (e.g., showing pornography, genitals, or masturbating in front of a woman). But for many other behaviors, there are considerable gaps or differences between the two groups. One factor to consider is the infrastructure surrounding mobility and public transport facilities in cities such as Delhi, which is woefully inadequate for the city's population size, and the consequences these factors have on women's experiences. Many of the behaviors recognized as SH in public spaces listed in research do not lend themselves to being convenient for filing formal complaints. For instance, SH behaviors in public spaces such as unwanted sexual comments or remarks about clothing or anatomy or leaning closely or pushing against a woman in crowded situations (a quick Google search for images of crowded buses in India will offer an imagery and context) can be vague and leaves no evidence. The researchers traveled in public buses to gain first-hand experience when the data for the study were gathered in Delhi in 2014. Often, there are long lines at public bus stops and metro stations most all day. When buses arrive at a bus stop, they are tightly packed and leaning like sardines and leaning to one side with the weight of the people hanging on to any little foothold they can find, leaving no room for people to either get out or get in. Passengers are often reluctant to move to let people out for fear of losing their spot on the bus as new passengers push in to find any standing room that is available. The conditions are often chaotic with every passenger's single-minded goal being to board the bus. Given these physical conditions, identifying the perpetrator or the motive for some of the SH behaviors in public spaces becomes complicated. These factors are important precursors for researchers and policymakers to pursue in efforts to ameliorate $\mathrm{SH}$ problems.

Another area for possible future direction in research relates to patterns of offending. The offending patterns of the self and male friends are closely aligned, suggesting a couple of possibilities. The first is that sexual harassment occurs in a group context; that is, rather than an offender acting out alone, they are more likely to perpetrate in groups. The second possibility is that for some SH behaviors where detection is likely (e.g., touching/squeezing breasts) the degree of risk associated with detection or confrontation may result in the offender being more voyeuristic and self-indulgent, resulting in a slighter bigger margin; that is, relatively less concordance with the offender's own behavior. Finally, for some behaviors (e.g., touch/pinching or leaning closely) that occur in packed, moving buses in Indian cities where entry and exit from buses is difficult, physical contact between humans is virtually impossible to avoid under such circumstances. Perhaps offenders and victims' perspectives on similar behaviors could differ in terms of offending and victimization. Unfortunately, we do not have the data to draw inferences to these assumptions other than to consider them as important issues for future research.

\subsection{Conclusion and policy implications}

Profound issues stemming from globalization and traditional cultural tendencies have created unfavorable settings for women in public spaces. $\mathrm{SH}$ as a specific 
form of sexual violence in South Asian countries draws greater attention because of the disjunction between the prevalence of sexual harassment and the governments' inability to counteract such phenomena (Niaz, 2003). Findings from this research draw attention to two important factors from policy perspectives. The first relates to mobility and access to quality public transit infrastructure to create a greater sense of safety and security for women to participate and contribute to the overall economic and social advancement of the nation. As evidenced in this study and others, infrastructure can play a large part in the degree and prevalence of SH (e.g., overcrowded buses). As such, a goal of any democratic nation should be to demonstrate fair and equal treatment of all its citizens, including keeping women safe from $\mathrm{SH}$ wherever possible.

The second factor relates to the state's demonstration of its ability to effectively enforce the laws to reach a degree of deterrence in the eyes and minds of potential offenders. The large number of $\mathrm{SH}$ offenders that do not believe the state has either effective laws or effective enforcement of SH laws speaks volumes and could increase boldness among perpetrators of violence against women in public spaces. In addition, the state educational departments could institute curricular changes to introduce subject matter in schools to educate and sensitize students to this subject from an early age. Finally, findings from this research also point to the importance of media in educating the public about criminal laws and penalties relating to $\mathrm{SH}$ for both potential victims and potential offenders. Given the large fan following that entertainment and sports personalities enjoy in India, the media can play a critical role in bringing public service messages and dedicated news coverage of this form of social problem to a larger audience.

\section{References}

Acker, J. (1992). Gendered institutions: from sex roles to gendered institutions. Contemporary Sociology, 21, 565-569.

Badami, M. G., \& Haider, M. (2007). An analysis of public bus transit performance in Indian cities. Transportation Research Part A: Policy and Practice, 41, 961-981.

Bharucha, J., \& Khatri, R. (2018). The sexual street harassment battle: perceptions of women in urban India. The Journal of Adult Protection, 20, 101-109.

Bhatt, A., Menon, R., \& Khan, A. (2018). Women's Safety in Public Transport: A Pilot Initiative in Bhopal. Gurgaon, India: WRI Ross Center for Sustainable Cities.

Bhattacharyya, R. (2015). Understanding the spatialities of sexual assault against Indian women in India. Gender, Place \& Culture, 22, 1340-1356.

Bhattacharyya, R. (2016). Street violence against women in India: mapping prevention strategies. Asian Social Work and Policy Review, 10, 311-325.

Ceccato, V. (2014). The nature of rape places. Journal of Environmental Psychology, 40, 97-107.

Ceccato, V., \& Paz, Y. (2017). Crime in São Paulo's metro system: sexual crimes against women. Crime Prevention and Community Safety, 19, 211-226.

Chockalingam, K., \& Vijaya, A. (2008). Sexual harassment of women in public transport in Chennai City: a victimological perspective. The Indian Journal of Criminology of Criminalistics, 29, 167-184. 


\section{Mahesh K. Nalla}

Cohen, L. E., \& Felson, M. (1979). Social change and crime rate trends: a routine activity approach. American Sociological Review, 44, 588-608.

Dhillon, M., \& Bakaya, S. (2014). Street harassment: a qualitative study of the experiences of young women in Delhi. SAGE Open, 4, 1-11.

Gaynair, G. (2013). ICRW survey: 95 percent of women and girls consider New Delhi unsafe. International Centre for Research on Women. www.icrw.org/news/icrwsurvey-95-percent-of-women-and-girls-consider-new-delhi-unsafe/ (accessed 19 August 2019).

Gurung, C. (2006). The Role of Women in the Fruit and Vegetable Supply Chain in Maharashtra and Tamil Nadu, India: The New and Expanded Social and Economic Opportunities for Vulnerable Groups Task Order Under the Women in Development IQC. Washington, DC: US Agency for International Development.

Hearn, J., \& Parkin, W. (2001). Gender, Sexuality, and Violence in Organizations. Thousand Oaks, CA: Sage.

Jagori \& UN Women (2011). Safe Cities Free of Violence Against Women and Girls Initiative: Report of the Baseline Survey Delhi 2010. New Delhi: Jagori \& UN Women.

Lea, S. G., D'Silva, E., \& Asok, A. (2017). Women's strategies addressing sexual harassment and assault on public buses: an analysis of crowdsourced data. Crime Prevention and Community Safety, 19, 227-239.

Luthar, H. K., \& Luthar, V. K. (2007). A theoretical framework explaining cross-cultural sexual harassment: integrating Hofstede and Schwartz. Journal of Labor Research, 28, 169-188.

MacKinnon, C. (1979). Sexual Harassment of Working Women: A Case of Sex Discrimination. New Haven, CT: Yale University Press.

Macmillan, R., Nierobisz, A., \& Welsh, S. (2000). Experiencing the streets: harassment and perceptions of safety among women. Journal of Research in Crime and Delinquency, 37, 306-322.

Madan, M., \& Nalla, M. K. (2016). Sexual harassment in public spaces: examining gender differences in perceived seriousness and victimization. International Criminal Justice Review, 26, 80-97.

Natarajan, M. (2016). Rapid assessment of "eve teasing" (sexual harassment) of young women during the commute to college In India. Crime Science, 5.

National Crime Records Bureau. (2015). Crime in India 2016. Delhi: Ministry of Home Affairs. https://timesofindia.indiatimes.com/realtime/Crime_in_India_2016_Complete_ PDF.PDF.

National Crime Records Bureau. (2017). Crime in India 2016. Delhi: Ministry of Home Affairs. https://timesofindia.indiatimes.com/realtime/Crime_in_India_2016_Complete_ PDF.PDF.

Neupane, G., \& Chesney-Lind, M. (2017). Violence against women on public transport in Nepal: sexual harassment and the spatial expression of male privilege. International Journal of Comparative and Applied Criminal Justice, 38, 23-38.

Niaz, U. (2003). Violence against women in South Asian countries. Archives of Women's Mental Health, 6, 173-184.

Parikh, A. (2018). Politics of presence: women's safety and respectability at night in Mumbai, India. Gender, Place \& Culture, 25, 695-710.

Phadke, S. (2005). "You can be lonely in a crowd" the production of safety in Mumbai. Indian Journal of Gender Studies, 12, 41-62.

Pucher, J., Korattyswaroopam, N., \& Ittyerah, N. (2004). The crisis of public transport in India: overwhelming needs but limited resources. Journal of Public Transportation, $7,1-20$. 
Sur, P. (2014). Safety in the urban outdoors: women negotiating fear of crime in the city of Kolkata. Journal of International Women's Studies, 15, 212-226.

Tripathi, K., Borrion, H., \& Belur, J. (2017). Sexual harassment of students on public transport: an exploratory study in Lucknow, India. Crime Prevention and Community Safety, 19, 240-250.

Tseloni, A., \& Pease, K. (2004). Repeat personal victimization: random effects, event dependence and unexplained heterogeneity. The British Journal of Criminology, 44, 931-945.

Uggen, C., \& Blackstone. A. (2004). Sexual harassment as a gendered expression of power. American Sociological Review, 69, 64-92. 